\title{
Intramucosal leiomyosarcoma of the stomach following hereditary retinoblastoma in childhood - a case report and review of the literature
}

\author{
Ursula Pauser*1 and Horst Grimm²
}

\author{
Address: ${ }^{1}$ Department of Pathology, University of Lübeck, Lübeck, Germany and 2Department of Endoscopic Surgery, University of Kiel, Kiel, \\ Germany \\ Email: Ursula Pauser* - upauser@gmx.de; Horst Grimm - hillgrimm@t-online.de \\ * Corresponding author
}

Published: 14 December 2008

World Journal of Surgical Oncology 2008, 6:131 doi:10.1186/1477-7819-6-131

This article is available from: http://www.wjso.com/content/6/I/I3।

(c) 2008 Pauser and Grimm; licensee BioMed Central Ltd.

This is an Open Access article distributed under the terms of the Creative Commons Attribution License (http://creativecommons.org/licenses/by/2.0), which permits unrestricted use, distribution, and reproduction in any medium, provided the original work is properly cited.
Received: 26 May 2008

Accepted: 14 December 2008

\begin{abstract}
Background: Leiomyosarcomas of the stomach are very rare. At the time of primary diagnosis the tumors are most often in advanced stage and the patients complain of abdominal pain due to large tumor size. Endosonographically, the tumors impress as submucous mass with suspicion to malignancy. Sarcomas following hereditary retinoblastoma in childhood are in generally located in the soft tissue. Structural alterations of the retinoblastoma gene $(R B I)$ seem to be involved in the pathogenesis.
\end{abstract}

Case presentation: A 37-year-old german male suffered from reflux disorder. In endoscopic examination a small polypous tumor was detected in the stomach. The resection specimen revealed an intramucosal leiomyosarcoma. At the age of one year, the patient had a retinoblastoma.

Conclusion: This is the unique report of an intramucosal gastric leiomyosarcoma and the first account of a gastric leiomyosarcoma after retinoblastoma in childhood. A careful clinical follow-up is advised because of increased risk of developing further metachronous malignancies.

\section{Background}

Leiomyosarcomas are of smooth muscle origin and develop in the soft tissue of the vessel wall and in the smooth muscle layer of visceral organs. In the gastrointestinal tract, they normally arise in the submucosa and bulge out the mucosa and serosa. They present most often in advanced tumor stage. In this case we report of an intramucosal gastric leiomyosarcoma. Medical history referred treatment of a retinoblastoma in childhood. Sarcomas following hereditary retinoblastoma are in generally located in the soft tissue. Structural alterations of $R B 1$ seem to be involved in the pathogenesis of the secondary malignancy after treatment of retinoblastoma.

\section{Case presentation}

A 37-year-old man with reflux symptomatic was sent to endoscopic examination. During the examination strabismus was striking. The patient reported about eye operation with 1 year of age, due to a retinoblastoma. Both eyes were affected. The right eye was enucleated. The left eye was treated with laser. There was no tumor relapse. A germline mutation in RB1 was detected in 1988. In family history there is no further case of retinoblastoma. Due to tumor prevention the patient underwent endoscopic examination. In gastroscopy, a $1 \mathrm{~cm}$ in diameter polypous lesion was found in the antrum of the stomach. It was suspicious to be a hyperplastic polyp or an adenoma of gas- 
tric mucosa. The polypous lesion was resected endoscopically and was sent to histopathological investigation. Representative $4 \mu \mathrm{m}$ sections of formalin-fixed, paraffin-embedded tissue from the tumor specimens were stained with hematoxylin and eosin (H\&E) and periodic acid-Schiff. Immunohistochemical staining was performed using the standard avidin-biotin method with antibodies against smooth muscle actin (SMA, 1:20, Dako Cytomation, Glostrup, Denmark), S100 (1:500, Dako Cytomation), CD34 (1:500, Immunotech, Marseille, France) and KIT (1:50, Dako Cytomation). The proliferative activity was assessed by staining the tissue with the antibody MiB-1 (1:100, Dako Cytomation).

The polypous lesion, $1 \mathrm{~cm}$ in diameter, showed regular foveolar gastric glands and a diffuse spindle cell infiltrate in the mucosa. The spindle cells were arranged in parallel and whorl like bundles. The nuclei were elongated with plump ends and focally mild atypia (Fig. 1). There was an increased mitotic rate with 20 mitotic figures in 50 high power fields. In the immunoassay, the tumor cells stained strongly positive for SMA (Fig. 2) and negative for KIT, CD34, and S100. The proliferative activity, identified by MiB-1, was approximately $20 \%$ (Fig. 3 ). The spindle cell infiltrate was classified as an unusual intramucosal leiomyosarcoma of low grade malignancy. The diagnosis was confirmed by a referee pathologist. The tumor achieved the resection mark of the biopsy focally. In endosonographic monitoring 4 weeks later, there was no tumor residuum observed. Because of tumor malignancy, mucosectomy followed. The biopsy revealed a scar next to regular mucosa and lamina muscularis mucosae. Tumor residuum was not seen. In the literature were neither data of tumor treatment nor data with long time follow-up of intramucosal leiomyosarcoma available. The clinical outcome was not predictable. According to an expert of the

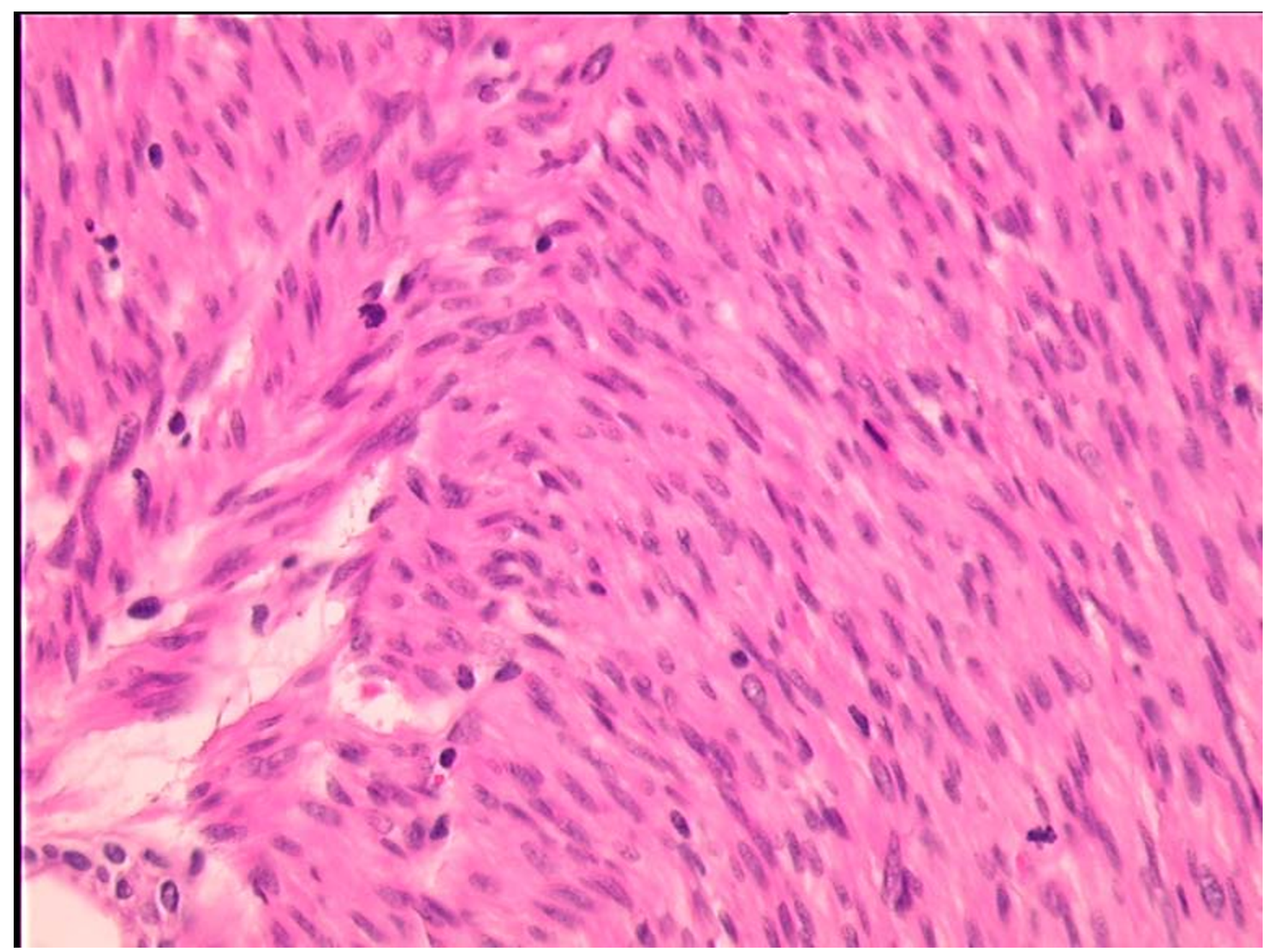

\section{Figure I}

Tumor infiltrate with spindle cells arranged in parallel bundles. The nuclei were elongated with plump ends and focally mild atypia. Several mitoses are shown (HE, original magnification $\times 400)$. 


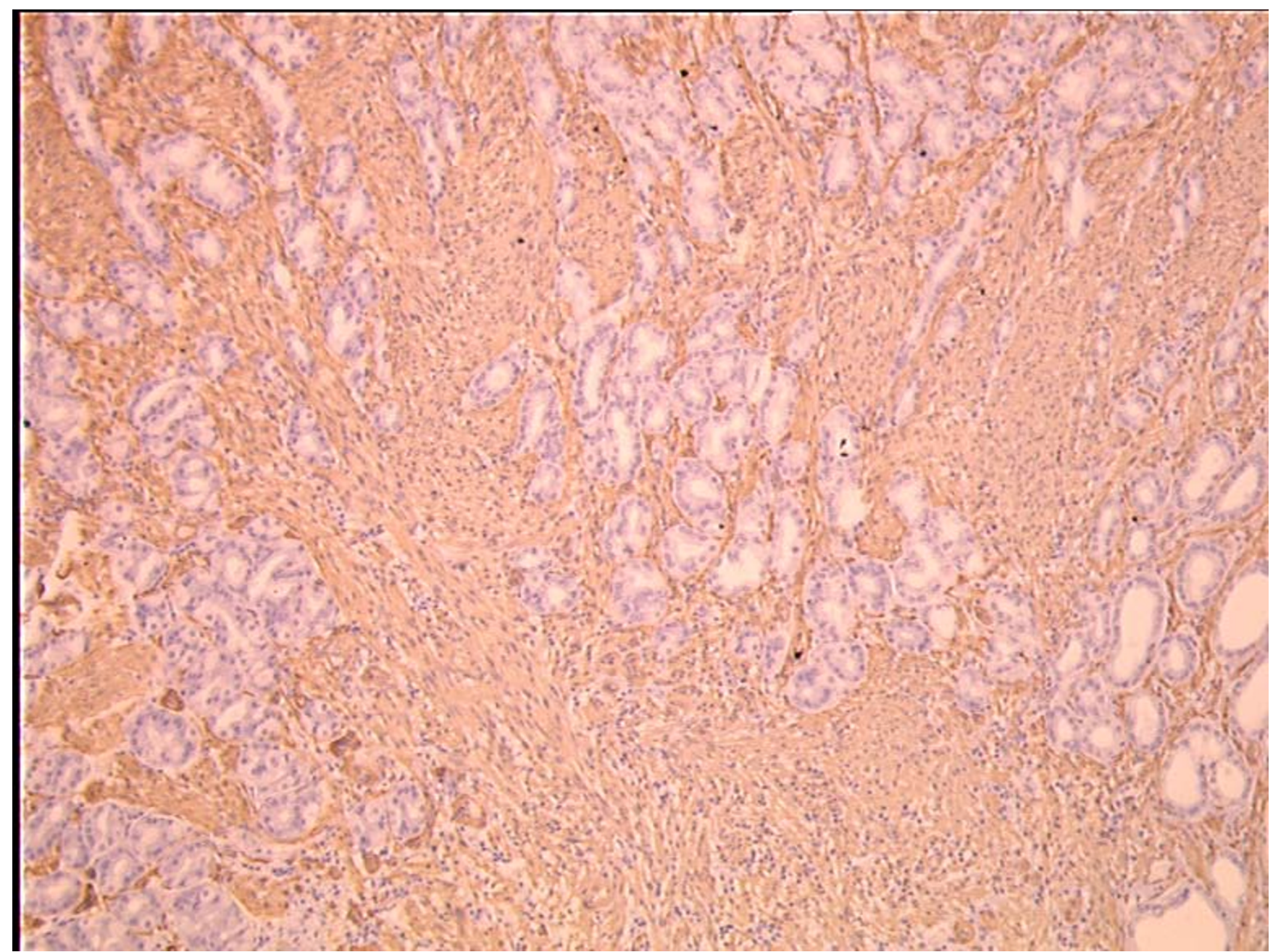

Figure 2

Immunohistochemical staining highlight the diffuse spindle cell infiltrate in the gastric mucosa. The tumor infiltrates the stroma between regular differentiated gastric glands. The tumor cells stain strongly positive for SMA. The preexisting gastric glands are negative (SMA, original magnification $\times 100)$.

European Sarcoma Study Group, a limited resection of the gastric antrum was recommended and done 4 weeks later. Reexamination revealed a chronic gastritis and a scar after mucosectomy, but no tumor residuum. Perigastric lymph nodes and a paracaval lymph node were free of tumor. A R0-resection with high safety of the resection margin was achieved. The endoscopic and endosonographic followup was inconspicuous since 3 years.

\section{Discussion}

Leiomyosarcomas of the stomach are rare. They usually present in older age and are typically of high grade malignancy (WHO 2000). They arise from the smooth muscle of gastric wall and were mostly located in the submucosa. The histological diagnosis of a leiomyosarcoma is unequivocal on the basis of the immunohistochemical expression of SMA. At the time of primary diagnosis the tumor size is normally large. Complete tumor resection is the standard treatment. The reported case was exceptionally, clinical and histological. The leiomyosarcoma resembled a polyp of the gastric mucosa without criteria of a stromal tumor or signs of malignancy. The tumor was limited to the mucosa, showed mild nuclear atypia but a high proliferative activity. It is the unique intramucosal leiomyosarcoma of the stomach and the first gastric leiomyosarcoma described in a survivor of a retinoblastoma in childhood. Because of the young age of the patient, the high proliferative activity of the tumor and the visceral tumor site, a resection with large tumor free margins was striving. There is an increased risk for the development of a metachronous malignancy following hereditary retinoblastoma due to the prior treatment and/or genetic susceptibility of $R B 1[1,2]$. Alterations in $R B 1$ are thoroughly investigated in soft tissue tumors [3]. Most often are oste- 


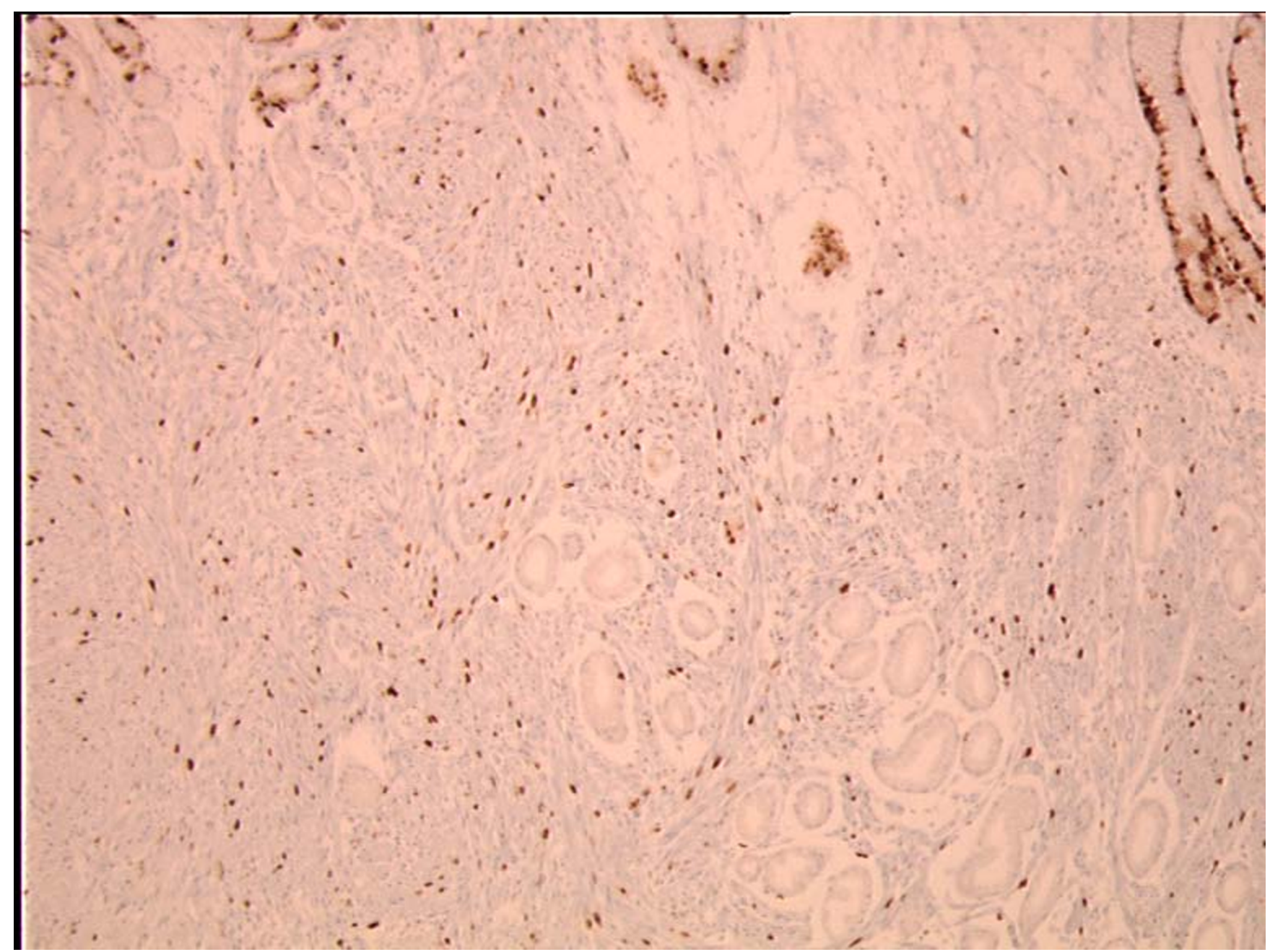

Figure 3

The proliferative activity of the tumor infiltrate, identified by MiB-I, is approximately $\mathbf{2 0} \%$. There is a normal proliferative activity of epithelial cells in the bottom of foveolar gastric glands (MIB-I, original magnification $\times 100$ ).

osarcomas, followed by soft tissue sarcomas. One study reported about three patients with leiomyosarcoma of the soft tissue, in the radiation field of a primary malignancy in childhood, 11 to 13 years earlier [1]. A leiomyosarcoma of the liver was detected in a 39-year-old woman, who has been treated 37 years before, for hereditary retinoblastoma of the eye [4]. A leiomyosarcoma in the maxillofacial region, followed by a chorioncarcinoma 5 years later, was described in a long-term follow up after treatment of a bilateral retinoblastoma [5]. Visceral leiomyosarcoma of the urinary bladder is reported in two cases, 38 years and 47 years after hereditary retinoblastoma [6,7]. The patients had a tumor free survival of about 3 decades between retinoblastoma and second malignancies. This is in common with our case. Similar results were reported in a large cohort of retinoblastoma patients recently [2]. However, 15 out of 23 leiomyosarcoma occurred outside the radiation field of retinoblastoma. Most frequently were uterine leiomyosarcoma. It seems unlikely that the radiation exposure caused the leiomyosarcoma. Moreover a radiation - induced chromosome instability of single normal RB1 copy seems to be involved in tumor development. Radiation combined with chemotherapy was associated with a heightened risk for leiomyosarcoma in this study.

Since neither radiation nor chemotherapy treatment is reported in our case, primary genetic alterations, i.e. in RB1 may have a protooncogenetic effect on the development of secondary malignancies. As described earlier there is an increased risk to develop a third tumor.

\section{Conclusion}

This is the unique report of an intramucosal gastric leiomyosarcoma and the first account of a gastric leiomyosarcoma after retinoblastoma in childhood. A careful clinical 
follow-up is advised because of increased risk of developing further metachronous malignancies.

\section{Consent}

Written informed consent was obtained from the patient for publication of this case report and accompanying images. A copy of the written consent is available for review by the Editor-in-Chief of this journal.

\section{Competing interests}

The authors declare that they have no competing interests.

\section{Authors' contributions}

UP drafted the manuscript with review of the literature and took the microscopic imaging.

HG participated in the care of the patient, contributed the clinical data and revised the manuscript for intellectual content and given final approval of the version to be published.

Both of the authors read and approved the final manuscript.

\section{References}

I. Bisogno G, Sotti G, Nowicki Y, Ferrari A, Garaventa A, Zanetti I, Favre C, Schiavetti A, Tamaro P, Carli M: Soft tissue sarcoma as a second malignant neoplasm in the pediatric age group. Cancer 2004, 100: 1758-1765.

2. Kleinerman RA, Tucker MA, Abramson DH, Seddon JM, Tarone RE, Fraumeni JF Jr: Risk of soft tissue sarcomas by individual subtype in survivors of hereditary retinoblastoma. J Natl Cancer Inst 2007, 99:24-31.

3. Stratton MR, Williams S, Fisher C, Ball A, Westbury G, Gusterson BA, Fletcher CD, Knight JC, Fung YK, Reeves BR: Structural alterations of the RB I gene in human soft tissue tumours. $\mathrm{Br}$ / Cancer 1989, 60:202-205.

4. Abdelli N, Thiefin G, Diebold MD, Bouche O, Aucouturier JP, Zeitoun $P$ : Primary leiomyosarcoma of the liver $\mathbf{3 7}$ years after successful treatment of hereditary retinoblastoma. Gastroenterol Clin Biol 1996, 20:502-505.

5. Marta U, Zsuzsanna S, Jozsef B, Zsolt N, Bela S, Gyorgy S: Rare incidence of three consecutive primary tumors in the maxillofacial region: retinoblastoma, leiomyosarcoma, and choriocarcinoma: case report. J Craniofac Surg 200 I, 12:464-468.

6. Liang SX, Lakshmanan Y, Woda BA, Jiang Z: A high-grade primary leiomyosarcoma of the bladder in a survivor of retinoblastoma. Arch Pathol Lab Med 200I, I 25(9): I23I-I234.

7. Venkatraman L, Goepel JR, Steele K, Dobbs SP, Lyness RW, McCluggage WG: Soft tissue, pelvic, and urinary bladder leiomyosarcoma as second neoplasm following hereditary retinoblastoma. J Clin Pathol 2003, 56:233-236.
Publish with Biomed Central and every scientist can read your work free of charge

"BioMed Central will be the most significant development for disseminating the results of biomedical research in our lifetime. "

Sir Paul Nurse, Cancer Research UK

Your research papers will be:

- available free of charge to the entire biomedical community

- peer reviewed and published immediately upon acceptance

- cited in PubMed and archived on PubMed Central

- yours - you keep the copyright 